\title{
The Dharma of Nonsense-Mediated mRNA Decay in Mammalian Cells
}

\author{
Maximilian Wei-Lin Popp ${ }^{1,2}$, and Lynne E. Maquat ${ }^{1,2, *}$
}

\begin{abstract}
Mammalian-cell messenger RNAs (mRNAs) are generated in the nucleus from precursor RNAs (pre-mRNAs, which often contain one or more introns) that are complexed with an array of incompletely inventoried proteins. During their biogenesis, pre-mRNAs and their derivative mRNAs are subject to extensive cis-modifications. These modifications promote the binding of distinct polypeptides that mediate a diverse array of functions needed for mRNA metabolism, including nuclear export, inspection by the nonsense-mediated mRNA decay (NMD) quality-control machinery, and synthesis of the encoded protein product. Ribonucleoprotein complex (RNP) remodeling through the loss and gain of protein constituents before and after premRNA splicing, during mRNA export, and within the cytoplasm facilitates NMD, ensuring integrity of the transcriptome. Here we review the mRNP rearrangements that culminate in detection and elimination of faulty transcripts by mammalian-cell NMD.
\end{abstract}

\section{INTRODUCTION}

All cellular processes are not without errors. Accordingly, the cell has evolved complex quality-control mechanisms aimed at dealing with its own mistakes. One particularly prevalent and deleterious error is the introduction of a premature termination codon (PTC) within a protein encoding exon. This could occur as a result of faulty gene transcription, non-productive somatic rearrangements of T-cell receptor (TCR) or B-cell receptor (BCR) genes that generate immune receptor diversity necessary to keep pathogens at bay, or faulty pre-mRNA splicing. In all cases, the resulting PTC-containing transcripts must be recognized and eliminated before the truncated proteins that they encode accumulate in the cell. Failure to do so has pathological consequences in humans, as evidenced by the $\sim 33 \%$ of inherited and acquired diseases that are a result of PTC acquisition

\footnotetext{
${ }^{1}$ Department of Biochemistry and Biophysics, School of Medicine and Dentistry, ${ }^{2}$ Center for RNA Biology, University of Rochester, Rochester, New York 14642, USA

*Correspondence: lynne_maquat@urmc.rochester.edu Received 3 July, 2013; accepted 6 July, 2013; published online 27 Jan-
uary, 2014
}

Keywords: RNA metabolism, RNP remodeling, mRNA quality control, nonsense-mediated mRNA decay, premature termination codon
(Frischmeyer and Dietz, 1999). For example, dominantly inherited forms of $\beta$-thalassemia are caused by PTCs in human $\beta$ globin mRNA that escape NMD quality control, generating a truncated dominantly negative-acting polypeptide that disrupts hemoglobin structure and function (Kugler et al., 1995). A range of other pathologies are also caused by the failure of NMD to eliminate PTC-containing transcripts (Bhuvanagiri et al., 2010; Holbrook et al., 2006), illustrating the immediate relevance of this process to human health.

The mechanism by which NMD exerts its protective effect is intertwined with the biogenesis of its targets, namely, mRNAs. mRNAs are bound by protein constituents as messenger ribonucleoprotein complexes (mRNPs) as soon as they are produced and subsequently during their cellular lifetime. In a process termed remodeling, the polypeptide components of these mRNPs are subject to constant rearrangements, with some components being expelled, new components joining, and others simply moving spatially on the mRNA. Here we review how these molecular gymnastics facilitate NMD, pointing out where gaps in our knowledge exist.

\section{mRNA BIOGENESIS}

Mammalian-cell mRNAs and the primary transcript from which they derive exist not as naked ribonucleic acids, but rather in complex with an assortment of proteins. These proteins begin associating with primary transcripts during their synthesis by RNA polymerase II (pol II) in a series of pre-mRNA processing steps. These steps ultimately impinge on the mechanism of NMD since they result in the addition of proteins and other RNA modifications that affect inspection and decay of the product mRNA by the NMD apparatus. We provide a thumbnail sketch of only the major nuclear pre-mRNA and/or mRNA cis-modifications that take place in mammalian cells in order to set the stage for discussing how these modifications affect NMD (Fig. 1).

\section{5 ' capping}

As soon as the nascent transcript emerges from the surface of pol II, it is cotranscriptionally capped at its $5^{\prime}$ end with a 7methylguanosine residue. This cap is added in an unusual $5^{\prime}-$ to- 5 ' linkage to the first transcribed residue of the transcript. In vertebrates, the ribose moieties of the first and second residues are also methylated at their $2^{\prime}$ hydroxyl groups. Capping provides a protective function by counteracting nuclear $5^{\prime}$-to- $3^{\prime}$ exoribonucleases, which are unable to hydrolyze the linkage 
between a 7-methylguanosine and the first templated RNA residue. Capping also provides a binding platform for the capbinding complex (CBC), which is composed of the cap-binding protein 80 (CBP80) and CBP20. Capping enhances pre-mRNA splicing, pre-mRNA $3^{\prime}$-end processing, mRNA export to the cytoplasm, and mRNA translation (Topisirovic et al., 2011). Capping enzymes associate with the phosphorylated C-terminal domain (CTD) of pol II (McCracken et al., 1997). This domain, which is unique to pol II, is phosphorylated by transcription factor II $\mathrm{H}$ (TFIIH) during transcription initiation, at once explaining how transcripts are capped cotranscriptionally and also why only pol II products (and not tRNAs, rRNAs, etc) are earmarked with this unique $5^{\prime}$ feature.

\section{Splicing}

Mammalian-gene exons are interrupted by stretches of intervening material termed introns. These introns must be spliced out of the nascent pre-mRNA, and the resulting exons must be joined together to give rise to a mature mRNA that accurately transmits its encoded information to the protein synthesis machinery. Splicing, which is an extremely complex process, is the purview of macromolecular machines termed spliceosomes, themselves comprised of RNAs (small nuclear RNAs, snRNAs) as well as splicing factors and other proteins. While the exact details are beyond the scope of this review (the reader is referred to: (Braunschweig et al., 2013; Hoskins and Moore, 2012; Kornblihtt et al., 2013), the spliceosome generally recognizes short conserved sequences in pre-mRNAs and catalyzes a series of two transesterification reactions that result in precise phosphodiester bond formation between two exons. Pertinent to mammalian-cell NMD, a consequence of the splicing reaction is the deposition of another large macromolecular complex, termed the exon-junction complex (EJC), 24 nucleotides upstream of exon-exon borders (Le Hir et al., 2000a; 2000b; Singh et al., 2012). EJCs assist in both nuclear export of the mRNP via RNA Export Factor (REF) and, as discussed below, NMD. The core EJC consists of the DEAD-box RNA helicase eukaryotic translation initiation factor $4 \mathrm{~A} 3$ (elF4A3), which is not actually a translation initation factor. As part of the EJC, elF4A3 is bound tightly to the RNA, and its ATPase activity is inhibited by partner-binding proteins $\mathrm{Y} 14$ and Magoh so as to result in mRNA sequence-independent anchorage of the EJC (Ballut et al., 2005). MLN51 also stabilizes the complex, forming a platform to which additional EJC factors (such as REF) can bind. An emerging theme is that the peripheral EJC constituents are heterogeneous and promote multiple downstream RNA metabolic processes, including nuclear export, translation, and inspection by the NMD machinery (see below). The exon-exon junctions at which EJCs are deposited, too, are heterogeneous, and some junctions are devoid of EJCs despite having formed via a splicing reaction (Singh et al., 2012).

\section{$3^{\prime}$ polyadenylation}

Like the $5^{\prime}$ end, the $3^{\prime}$ end of eukaryotic pre-mRNAs is modified, in this case first through a hydrolysis reaction followed by the addition of a series of non-templated $A$ residues (Millevoi and Vagner, 2010; Shatkin and Manley, 2000). The signal for polyadenylation is generally an AAUAAA sequence, located roughly 10-35 nucleotides upstream of the future poly $(A)$ tail, followed by a G/U rich sequen-ce downstream of the cleavage and polyadenylation site. These sequences serve to recruit cleavage and specificity factor (CPSF) and the cleavage stimulatory factor (CStF), respectively. Among others, three additional polypeptides, cleavage factor I (CFI) and cleavage factor II (CFII), as well as poly $(\mathrm{A})$ polymerase (PAP) bind to this complex. Binding of PAP allows cleavage to proceed and also produces a high local concentration of the polymerase necessary for polyadenylation, ensuring that the reaction will be completed before exonucleases have the opportunity to act on the vulnerable newly generated $3^{\prime}$ hydroxyl group. PAP slowly adds A residues to the new $3^{\prime}$ end until a length sufficient for poly $(A)$ binding protein nuclear 1 (PABPN1) association is created. PABPN1 association with short poly $(A)$ tails stimulates the rate of polyadenylation by PAP (Kuhn et al., 2009), culminating in a poly $(A)$ tail of roughly $200-250$ residues to which both PABPN1 and its largely cytoplasmic counterpart PABPC1 are bound in the nucleus (Hosoda et al., 2006).

\section{mRNP EXPORT}

Once proper $5^{\prime}$ and $3^{\prime}$ modifications as well as splicing have been completed, the mRNA, assembled as an mRNP, must traverse the physical barrier between the nucleus and cytoplasm, so as to arrive at the location where functionally active ribosomes, translation initiation factors, and the rest of the protein production machinery reside (Burns and Wente, 2012; Cole and Scarcelli, 2006). The nucleus is a double membranedelimited compartment with proteinacious nuclear pore complexes (NPCs) facilitating the movement of macromolecules between the nucleoplasm and cytoplasm (Burns and Wente, 2012; Tran and Wente, 2006). As discussed above, passage of mRNPs through the NPC is facilitated by RNA cis-modifications and the proteins that bind them. In addition, the nuclear import of protein cargoes is facilitated by a group of proteins termed karyopherins. The karyopherin importin- $\alpha$ binds to the bipartite nuclear localization signals in the CBP80 constituent of CBC to promote the import of $\mathrm{CBC}$ into nuclei. In an unusual association that does not result in dissociation of importin- $\alpha$ and CBP80, the CBC of newly synthesized nuclear mRNA remains bound by importin- $\alpha$, which vectorially translocates with the mRNP through nuclear pores into the cytoplasm in a mechanism that uses a gradient of the monomeric $G$ protein Ran, which is bound to the GTP nucleotide for directionality (Dias et al., 2010) An important consequence of mRNP export is mRNP remodeling. Some proteins bound to mRNP in the nucleus dissociate and are replaced by other proteins in the cytoplasm. This process of remodeling involves replacement of $5^{\prime}$ cap-bound CBC by elF4E via importin- $\beta$ (Dias et al., 2009; Sato and Maquat, 2009), removal of EJCs via ribosome-bound PYM (Gehring et al., 2009b), and replacement of PABPN1 by PABPC1 in an unknown but translation-promoted mechanism (Sato and Maquat, 2009). Each remodeling event alters the efficiency of NMD (Fig. 1 ; see below).

\section{CYTOPLASMIC EVENTS: NMD}

With the newly exported mRNP localized to the cytosol, the stage is set for the NMD surveillance machinery to inspect the transcript for an in-frame PTC and, in so doing, decide whether the mRNA should be spared for the production of full-length functional protein or earmarked for destruction because it encodes a truncated protein that is potentially deleterious to cellular metabolism. We shall first discuss a simplified current working model for the remodeling events that culminate in EJCdependent NMD. We follow this by a discussion of points where our knowledge is incomplete. 


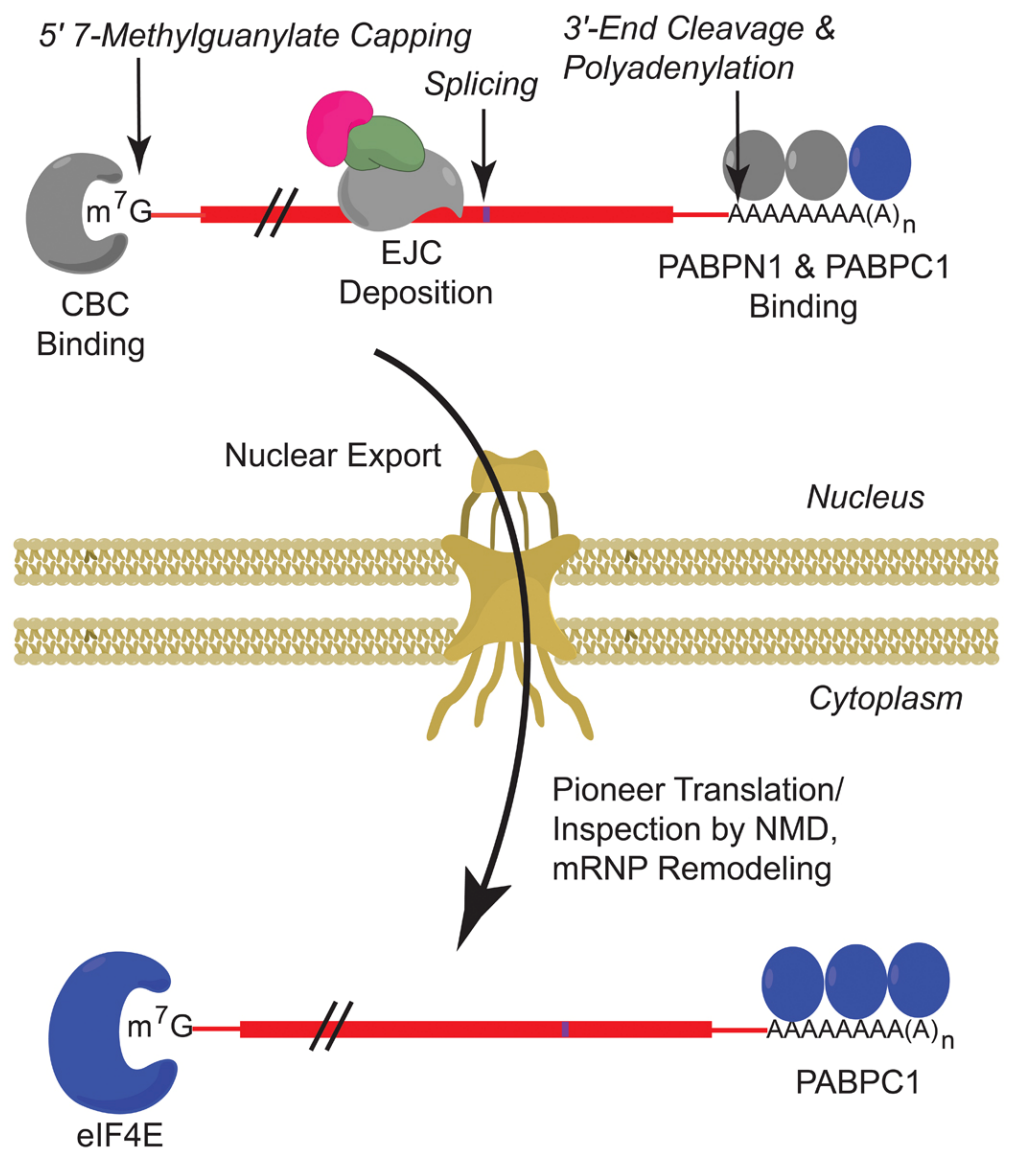

Fig. 1. Cis-modifications and Select Proteins Bound to mRNAs in the Nucleus versus the Cytoplasm. During transcription in the nucleus, pre-mRNAs are subject to $5^{\prime}$ capping with a 7-methylguanylate residue in $5^{\prime}$-to- $5^{\prime}$ linkage to the nascent transcript. This facilitates binding by the cap-binding complex (CBC), which is composed of cap-binding protein 80 (CBP80) and CBP20. Co- and post-transcriptionally, introns are removed and exons are joined together in a process called pre-mRNA splicing. A consequence of splicing is deposition of an exon-junction complex (EJC) 24 nucleotides upstream of exon-exon borders. At their $3^{\prime}$ end, transcripts undergo cleavage and polyadenylation, which allows poly $(A)$-binding protein nuclear 1 (PABPN1) and poly(A)-binding protein cytoplasmic 1 (PABPC1) to bind. This assembled mRNP is exported through the nuclear pore complex into the cytoplasm. Immediately after export, the mRNP is subject to pioneer translation and, during this process, inspection by NMD. The mRNP is further remodeled in processes that either are or are not augmented by translation. Select events include replacement of $\mathrm{CBC}$ by elF4E, which is the cap-binding component of the elF4F complex; removal of EJCs via ribosome-associated PYM and early rounds of translation; and replacement of PABPN1 by PABPC1, which is likewise augmented by early rounds of translation. NMD takes place during these dynamic events (see Fig. 2). Successful negotiation of NMD spares the remodeled mRNA from degradation and allows it to template protein production. Horizontal red lines, 5'- and $3^{\prime}$ - untranslated regions; horizontal red bar, coding region; vertical purple bar, exon-exon junction.

\section{NMD: the parts list}

Recognition of a PTC as aberrant and the subsequent degradation of a PTC-bearing mRNA are subjects of intense ongoing research (Hwang and Kim, 2013). Mammalian-cell NMD, which depends on translation for PTC recognition, is thought to occur rapidly after mRNP export. Indeed, the kinetics of NMD, as examined using single-RNA fluorescence in-situ hybridization (FISH) of PTC-containing transcripts, supports this notion (Trcek et al., 2013). NMD is facilitated by a group of protein trans-effectors. Conserved in all organisms known to support NMD, the core group of NMD factors consists of up-frameshift proteins UPF1, UPF2 and UPF3 (Fig. 2). In mammals, UPF3 has been diversified to consist of two variants, UPF3 (UPF3a) and UPF3X (UPF3b), which derive from separate genes (Serin et al., 2011). Additional factors include the suppressor with morphological effects on genitalia proteins SMG1, SMG5, SMG6, SMG7, SMG8, and SMG9 (Isken and Maquat, 2007; Mühlemann and Lykke-Andersen, 2010; Rebbapragada and Lykke-Andersen, 2009).

\section{NMD: mechanism}

In mammals, the EJC mark left behind on mRNA as a consequence of pre-mRNA splicing seems to be a critical factor in the decision as to whether an mRNA is aberrant or not (Le Hir et al., 2000a; 2000b). Most termination codons reside in the final exon. Thus a situation where a termination codon resides $5^{\prime}$ to an EJC results in an unusual configuration. NMD is a translationdependent process, and translation termination is used to relay the position of a PTC to the NMD apparatus. Termination requires eukaryotic release factor 1 (eRF1) and eRF3. If termination occurs $\geq 50-55$ nucleotides upstream of an EJC (the 5055 nucleotide rule; Nagy and Maquat, 1998), the size of the terminating ribosome is insufficient to physically remove the EJC. Thus this configuration is characteristic of PTC-containing mRNAs and not of most normal endogenous mRNAs (exceptions exist, of course), but how are these signals conveyed to the NMD surveillance apparatus?

The key NMD factor, UPF1, is an ATP-dependent RNA helicase that associates with the terminating ribosome via an interaction with eRF3 (Czaplinski et al., 1998; Kashima et al., 2006). A considerable amount of data indicate that this takes place shortly after mRNA export, while mRNA remains bound to CBC during what is termed a "pioneer" round of translation (Ishigaki et al., 2001; Maquat et al., 2010a; 2010b). Importantly the pioneer round of translation involves newly synthesized CBCbound mRNA prior to the cytoplasmic remodeling step that replaces cap-bound $\mathrm{CBC}$ by elF4E and is compatible with the observed NMD kinetics (Trcek et al., 2013 and references therein). CBP80 has also been documented to "chaperone" UPF1 to the terminating ribosome (Hwang et al., 2010), located at the PTC, helping to form what is termed the "SURF" complex, which consists of the serine/threonine kinase SMG1 (whose activity is initially dampened by the presence of SMG8-SMG9), UPF1, and eRF1-eRF3 (Kashima et al., 2006). Meanwhile, the EJC is decorated with UPF3 or UPF3X which associates with UPF2. In a mechanism that may involve "reeling in" of the 
RNP Rearrangements before, during and after NMD

Maximilian Wei-Lin Popp \& Lynne E. Maquat
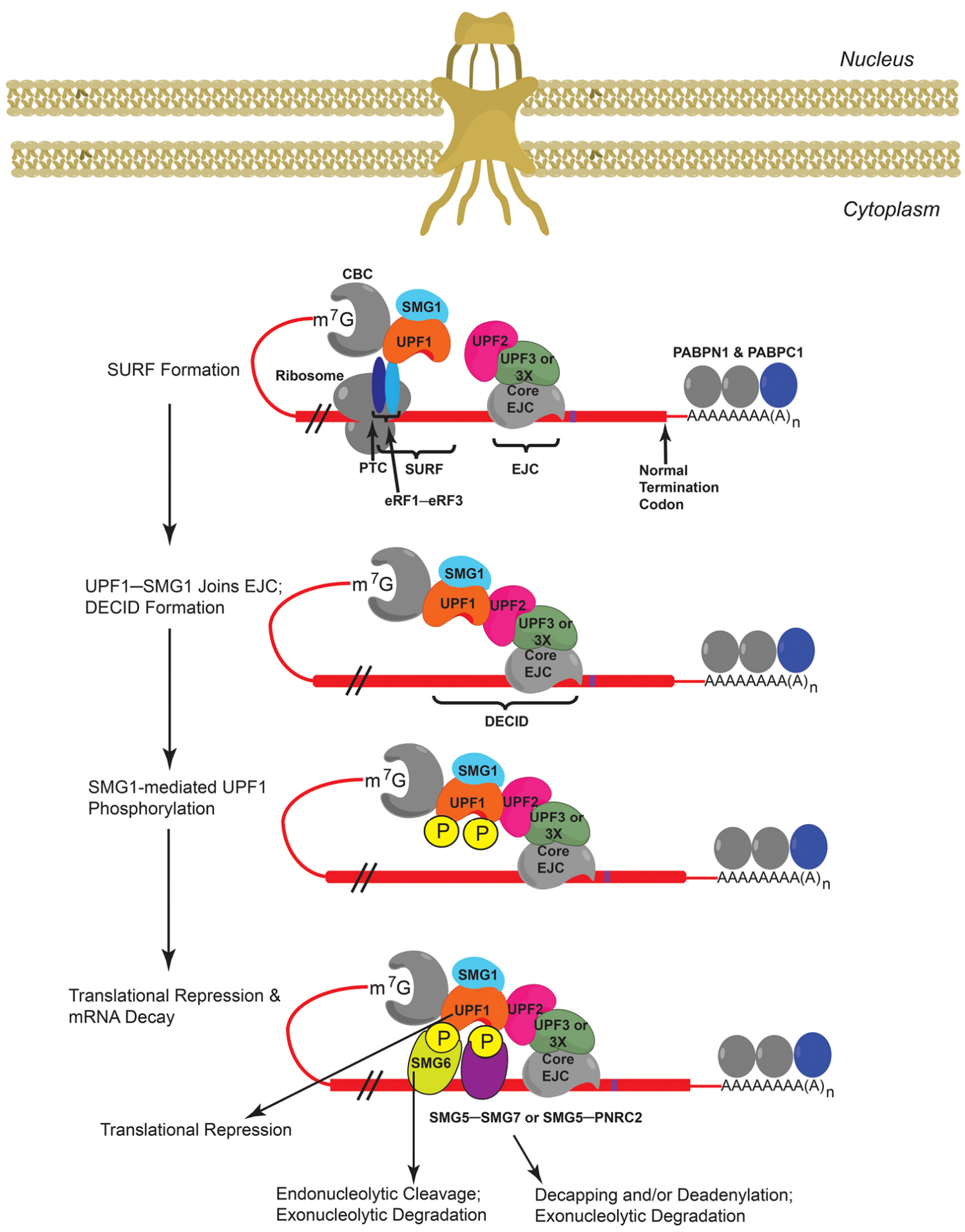

Fig. 2. Protein rearrangements during mammalian-cell, EJC-mediated NMD. Immediately after nuclear export, CBC-bound templates are subject to pioneer round(s) of translation. If a premature termination codon (PTC) resides $\geq 50-55$ nucleotides (nt) upstream of an exon-exon junction that is bound by an EJC, then CBC escorts UPF1-SMG1 to the eRF3 constituent of the eRF1-eRF3 heterodimer in the context of the terminating ribosome, forming the SURF complex (first, top). CBC also escorts UPF1-SMG1 to the EJC, to which UPF2 is bound via UPF3 or UPF3X (second) to form the DECID complex (which may also include eRF1 and eRF3; Kashima et al., 2006). In this configuration, SMG1 phosphorylates various serines and threonines near the $\mathrm{N}$ - and C-termini of UPF1 (third), producing hyperphosphorylated UPF1. UPF1 activation via phosphorylation has several functions (fourth, bottom). It induces translational repression, recruits SMG6 (which endonucleolytically cleaves PTC-bearing mRNAs between the PTC and EJC), and recruits SMG5-SMG7 or SMG5-PNRC2, which further recruit decapping and/or deadenylating enzymes, facilitating exonucleolytic degradation of the mRNA. See text for further details. 
mRNA spanning the PTC and the EJC (Shigeoka et al., 2012), UPF1 contacts UPF2 at the EJC, forming the decay-inducing complex (DECID) (Yamashita et al., 2009). Because both PTCbearing transcripts and their PTC-free counterparts associate to some degree with UPF1, albeit to different extents (Hogg and Goff, 2010; Kurosaki and Maquat, 2013), DECID formation (a consequence of EJC deposition) is critical in determining whether an mRNA is spared or sent for destruction. DECID formation leads to SMG1-mediated phosphorylation of UPF1 at multiple residues located within $\mathrm{N}$ - and C-terminal portions of UPF1. Hyperphosphorylation of UPF1 is prerequisite for destruction of PTC-bearing mRNAs. SMG1-induced phosphorylation of UPF1 functions to recruit the additional SMG factors, SMG6 and SMG5-SMG7 (Okada-Katsuhata et al., 2012), as well as proline-rich nuclear receptor co-regulatory protein 2 (PNRC2) (Cho et al., 2009). Recruitment of SMG6 to PTC-containing templates causes one or more endonucleolytic cleavages between the PTC and EJC. SMG6 mediates this cleavage itself, by virtue of its PilT N-terminus (PIN) domain (Eberle et al., 2009; Huntzinger et al., 2008). Endonucleolytic cleavage constitutes an irreversible step towards destruction as it generates mRNA ends unprotected by the usual $5^{\prime}$ and $3^{\prime}$ modifications discussed above. SMG5-SMG7 or SMG5-PNRC2 complexes may also be recruited by hyperphosphorylated UPF1. These adaptor complexes further recruit decapping enzymes and deadenylases that remove the crucial $5^{\prime}$ and $3^{\prime}$ modifications, allowing access to $5^{\prime}$-to- $3^{\prime}$ and $3^{\prime}$-to-5' RNA degradation enzymes, respectively (Fukuhara et al., 2005; Lejeune et al., 2003; Unterholzner and Izaurralde, 2004).

Binding of UPF2 to UPF1 (i.e. joining of all or part of SURF to the EJC to form the DECID complex) activates UPF1 helicase activity. This occurs when UPF2 binds the regulatory cysteinehistidine rich $(\mathrm{CH})$ domain of UPF1, causing a conformational change that has been documented by X-ray crystallography and that promotes UPF1 helicase activity (Chamieh et al., 2008; Chakrabarti et al., 2011). This activity is needed to strip the $3^{\prime}$-cleavage product generated by SMG6 of its protein components in order to provide access to the $5^{\prime}$-to- $3^{\prime}$ exonuclease XRN1 (Franks et al., 2010) and also to recycle essential protein factors.

Translational repression (through interference with translation initiation) has recently gained attention as a critical step towards microRNA-mediated mRNA degradation (Bazzini et al., 2012; Djuranovic et al., 2012; Meijer et al., 2013). In the context of NMD, translational repression has long been known to be a prerequisite for degradation (Isken et al., 2008). Hyperphosphorylated UPF1 functions to limit the amount of translation products that could arise from PTC-bearing mRNAs. It does so by interacting directly with elF3 of a $43 S$ (i.e. 40S/Met-tRNA ${ }_{i}^{\text {Met/ }}$ mRNA) pre-initiation complex that is poised at the AUG translation initiation codon of an mRNA once it is recognized to harbor a PTC. This inhibits the conversion of the $43 \mathrm{~S}$ complex to a translationally competent $80 S$ form.

Since NMD is a translation-dependent process, the fate of the encoded truncated polypeptide must be addressed by the cell. Truncated polypeptides may be toxic, exhibiting dominantnegative effects that contribute to a number of human pathologies. That NMD apparently evolved to safeguard against these types of insults raises the possibility that cells may be able to mediate destruction of a truncated polypeptide that results as a consequence of the pioneer round of translation, in addition to degrading the mRNA from which the truncated polypeptide derives. In yeast, several reports indicate that UPF1 is itself an E3 ubiquitin ligase that collaborates with an E2 enzyme (Kuro- ha et al., 2009; Takahashi et al., 2008). E3 enzymes mediate attachment of the 76-amino acid ubiquitin moiety onto proteins that are destined for proteasome-mediated destruction. This could provide a mechanism for rapid degradation of the truncated polypeptides that are byproducts of the pioneer round of translation of PTC-bearing mRNAs, although this notion bears much further investigation in mammalian cells since apparently not all truncated proteins are degraded (Anczukow et al., 2008).

A final consideration is how active, hyperphosphorylated UPF1 is recycled for further rounds of NMD. SMG5-SMG7 recruitment to phospho-UPF1 functions to further recruit protein phosphatase 2A (PP2A), which dephosphorylates UPF1, returning it to its inactive state (Anders et al., 2003; Chiu et al., 2003; Ohnishi et al., 2003).

\section{OTHER CYTOPLASMIC REMODELING EVENTS AND THEIR IMPACT ON NMD}

The events of NMD sketched above must be placed within their proper temporal framework. As mRNPs emerge from nuclear pores, they are remodeled to include cytoplasmic proteins, and the nuclear proteins that are stripped from the mRNPs are returned to the nucleus.

\section{$5^{\prime}$ remodeling}

At the mRNA $5^{\prime}$ end, the $\mathrm{CBC}$ is removed and replaced by elF4E. Surprisingly, it is not the initial round(s) of pioneer translation that promotes this event. Rather it is binding of importin- $\beta$ to CBP80-bound importin- $\alpha$ that facilitates replacement of CBC by elF4E (Sato and Maquat, 2009). Two recent papers suggest that mammalian NMD may not be largely restricted to CBCbound templates (Durand and Lykke-Andersen, 2013; Rufener and Muhlemann, 2013), as suggested previously (Trcek et al., 2013) and references therein. Thus it may be that in the cell, the kinetics of NMD-induced degradation merely correlates with the kinetics of $\mathrm{CBC}$ replacement by elF4E. In other words, NMD may occur more rapidly [the half-life of an NMD substrate once it reached the cytoplasm was determined to be $<1$ min by single-molecule FISH, (Trcek et al., 2013)] than the replacement of $\mathrm{CBC}$ by elF4E, blurring the distinction between causeand-correlation and seemingly confining NMD to CBC-bound templates. Such a situation leaves also the question of the disposition of EJC components on elF4E-bound templates, which are presumably physically removed by the ribosome during the initial rounds of CBC-mediated translation (Dostie and Dreyfuss, 2002; Gehring et al., 2009a; Sato and Maquat, 2009), yet are typically a requirement for NMD. Thus although elF4E-bound templates can be targeted for NMD (see e.g. Hosoda et al., 2005), where tethering UPF1 downstream of a termination codon triggers the NMD of both $\mathrm{CBC}$-bound and elF4E-bound mRNA), it may simply be the case that most mRNAs are destroyed sufficiently swiftly after their biogenesis that the cap has yet to be remodeled. In support (but not proof) of this, CBP80 augments the efficiency of NMD (Hwang et al., 2010).

\section{$3^{\prime}$ remodeling}

Unlike the exchange of $\mathrm{CBC}$ by elF4E, remodeling at the $3^{\prime}$ end of an NMD target is promoted by translation. After export, PABPN1 is replaced by its cytoplasmic counterpart PABPC1 (Sato and Maquat, 2009). This exchange has important consequences for the efficiency of NMD. Most elF4E-bound mRNAs likely adopt a circular conformation by virtue of the association of elF4G, which binds to elF4E at the mRNA cap, with PABPC1; 
this positions translation termination within the vicinity of translation initiation and facilitates further rounds of translation (Amrani et al., 2004; 2008; Kervestin and Jacobson, 2012). For CBCbound templates, circularization may be mediated either by PABPC1 binding to elF4G (Lejeune et al., 2004) or possibly to the elF4G-like molecule CBP80/20-dependent translation initiation factor (CTIF) (Choe et al., 2012; Kim et al., 2009), which in turn binds the CBC. Although the CTIF lacks the PABP interaction region present in elF4GI and elF4GIl, possible interactions between PABPC1 with other portions of CTIF remain to be tested. PABPC1 has been hypothesized to antagonize NMD by competitively blocking the interaction of UPF1 with eRF3 on the terminating ribosome, thus halting NMD before SURF formation occurs (Ivanov et al., 2008; Singh et al., 2008). However, it should be noted that there is no stringent proof of this and, in fact, PABPC1 is apparently not required to obviate NMD in yeast (Kervestin et al., 2012; Meaux et al., 2008). In situations where the termination codon is distant from the poly $(A)$ tail, as is the case with PTC-containing targets, the interaction of PABPC1 with eRF3 is proposed to be less efficient, allowing for NMD to proceed with possible stimulation from EJC components. This model also has been used to explain why AUG translation initiation codons that reside very close to PTCs fail to elicit efficient NMD, given that PABPC1 would be in close proximity to the PTC in a closed-loop conformation (Peixeiro et al., 2012). Notably, however, this effect has alternatively been attributed to translation reinitiation at a downstream AUG initiation codon (Neu-Yilik et al., 2011; Zhang and Maquat, 1997).

\section{CONCLUSION}

Open questions about the precise mechanism by which NMD destroys PTC-bearing transcripts remain. The picture that we have attempted to paint is one where NMD occurs on the backdrop of dynamic mRNP remodeling. Some of these events clearly play a causal role in NMD, but others may simply correlate with NMD kinetics. When viewed through this lens, the pressing issue of remodeling kinetics must be addressed. Exchange rates of $\mathrm{CBC}$ by elF4E will be of interest, and the possibility that this rate may be heterogeneous for distinct transcripts should be considered. As suggested by Izzauralde and Hentze (Hentze and Izaurralde, 2013), the dissociation rates of EJCs must also be investigated, and these may also likewise be heterogeneous.

With respect to the players that choreograph NMD, it is unlikely that the full complement of proteins impacting the efficiency of NMD has been revealed. For example, recent studies have uncovered a role for the human spliceosomal protein CWC22 in EJC deposition and NMD (Alexandrov et al., 2012). Even the RNA cis-features that render some transcripts subject to NMD remain incompletely understood. Abnormally long 3'UTRs, for example, may signal NMD-mediated destruction, but how this precisely fits within the better understood EJCmediated framework, aside from these abnormally long 3'UTRs binding unusually high levels of UPF1 (Hogg and Goff, 2010; Kurosaki and Maquat, 2013), remains to be determined. One possibility is a "unified" model (Singh et al., 2008) where NMD is a result of a competition between NMD antagonists (e.g. PABPC1) and agonists (e.g. the EJC). However, other transcripts with abnormally long $3^{\prime}$ UTRs evade NMD detection (Eberle et al., 2008). Is this accomplished in bona fide cellular transcripts by secondary structure in the $3^{\prime} U T R$ physically shortening the distance between the PTC and PABPC1, or are other mechanisms at play?
In addition to eliminating faulty transcripts, NMD has been implicated in regulating a large swath of the transcriptome, degrading many non-mutated transcripts [see e.g.(Mendell et al., 2004)]. Some of these transcripts bear structural features that would render them NMD targets but others do not. Which are direct NMD targets and which are indirectly targeted by NMD? What is the physiological purpose of endogenous transcript regulation via NMD, keeping in mind that transcripts encoding proteins with diverse functions seem to be targeted by NMD? For some classes of transcripts, such as RNA-binding proteins (in particular splicing factors) and the NMD factors themselves, NMD provides an autoregulatory loop that ensures homeostatic control of the genes encoding these transcripts (Huang et al., 2011; McGlincy and Smith, 2008; Ni et al., 2007; Saltzman et al., 2008; Yepiskoposyan et al., 2011). Although satisfying, this still leaves large groups of NMD-controlled transcripts unexplored. Can this system be regulated to accomplish physiologically important outcomes, for example via post-translational modifications of the NMD machinery? Although the exact mechanism by which NMD activity is acutely modulated remains to be discovered, recent studies suggest that this is the case, at least in the context of tumorigenesis and cellular stress (Gardner, 2010; Wang et al., 2011). These and other open questions should provide much fodder for interesting future research.

\section{ACKNOWLEDGMENTS}

M.W P. is a HHMI Post-doctoral Fellow of the Damon Runyon Cancer Research Foundation, DRG-2119-12. Research on NMD in the Maquat lab is supported by NIH R01 GM59614 to L.E.M.

\section{REFERENCES}

Alexandrov, A., Colognori, D., Shu, M.D., and Steitz, J.A. (2012). Human spliceosomal protein CWC22 plays a role in coupling splicing to exon junction complex deposition and nonsensemediated decay. Proc. Natl. Acad. Sci. USA 109, 21313-21318.

Amrani, N., Ganesan, R., Kervestin, S., Mangus, D.A., Ghosh, S., and Jacobson, A. (2004). A faux $3^{\prime}$-UTR promotes aberrant termination and triggers nonsense-mediated mRNA decay. Nature 432, 112-118.

Amrani, N., Ghosh, S., Mangus, D.A., and Jacobson, A. (2008). Translation factors promote the formation of two states of the closed-loop mRNP. Nature 453, 1276-1280.

Anczukow, O., Ware, M.D., Buisson, M., Zetoune, A.B., StoppaLyonnet, D., Sinilnikova, O.M., and Mazoyer, S. (2008). Does the nonsense-mediated mRNA decay mechanism prevent the synthesis of truncated BRCA1, CHK2, and p53 proteins? Hum. Mutat. 29, 65-73.

Anders, K.R., Grimson, A., and Anderson, P. (2003). SMG-5, required for $C$. elegans nonsense-mediated mRNA decay, associates with SMG-2 and protein phosphatase 2A. EMBO J. 22, 641-650

Ballut, L., Marchadier, B., Baguet, A., Tomasetto, C., Séraphin, B. and Le Hir, H. (2005). The exon junction core complex is locked onto RNA by inhibition of elF4AIll ATPase activity. Nat. Struct. Mol. Biol. 12, 861-869.

Bazzini, A.A., Lee, M.T., and Giraldez, A.J. (2012). Ribosome profiling shows that miR-430 reduces translation before causing mRNA decay in zebrafish. Science 336, 233-237.

Bhuvanagiri, M., Schlitter, A.M., Hentze, M.W., and Kulozik, A.E. (2010). NMD: RNA biology meets human genetic medicine. Biochem J. 430, 365-377.

Braunschweig, U., Gueroussov, S., Plocik, A.M., Graveley, B.R., and Blencowe, B.J. (2013). Dynamic integration of splicing within gene regulatory pathways. Cell 152, 1252-1269.

Burns, L.T., and Wente, S.R. (2012). Trafficking to uncharted territory of the nuclear envelope. Curr. Opin. Cell Biol. 24, 341-349.

Chakrabarti, S., Jayachandran, U., Bonneau, F., Fiorini, F., Basquin, 
C., Domcke, S., Le Hir, H., and Conti, E. (2011). Molecular mechanisms for the RNA-dependent ATPase activity of Upf1 and its regulation by Upf2. Mol. Cell 41, 693-703.

Chiu, S.Y., Serin, G., Ohara, O., and Maquat, L.E. (2003). Characterization of human Smg5/7a: a protein with similarities to Caenorhabditis elegans SMG5 and SMG7 that functions in the dephosphorylation of Upf1. RNA 9, 77-87.

Cho, H., Kim, K.M., and Kim, Y.K. (2009). Human proline-rich nuclear receptor coregulatory protein 2 mediates an interaction between mRNA surveillance machinery and decapping complex. Mol. Cell 33, 75-86.

Choe, J., Oh, N., Park, S., Lee, Y.K., Song, O.K., Locker, N., Chi, S.G., and Kim, Y.K. (2012). Translation initiation on mRNAs bound by nuclear cap-binding protein complex CBP80/20 requires interaction between CBP80/20-dependent translation initiation factor and eukaryotic translation initiation factor $3 \mathrm{~g}$. J. Biol. Chem. 287, 18500-18509.

Cole, C.N., and Scarcelli, J.J. (2006). Transport of messenger RNA from the nucleus to the cytoplasm. Curr. Opin. Cell Biol. 18, 299306.

Czaplinski, K., Ruiz-Echevarria, M.J., Paushkin, S.V., Han, X., Weng, Y., Perlick, H.A., Dietz, H.C., Ter-Avanesyan, M.D., and Peltz, S.W. (1998). The surveillance complex interacts with the translation release factors to enhance termination and degrade aberrant mRNAs. Genes Dev. 12, 1665-1677.

Dias, S.M., Wilson, K.F., Rojas, K.S., Ambrosio, A.L., and Cerione, R.A. (2009). The molecular basis for the regulation of the capbinding complex by the importins. Nat. Struct. Mol. Biol. 16, 930937.

Dias, S.M., Cerione, R.A., and Wilson, K.F. (2010). Unloading RNAs in the cytoplasm: an "importin" task. Nucleus 1, 139-143.

Djuranovic, S., Nahvi, A., and Green, R. (2012). miRNA-mediated gene silencing by translational repression followed by mRNA deadenylation and decay. Science 336, 237-240.

Dostie, J., and Dreyfuss, G. (2002). Translation is required to remove Y14 from mRNAs in the cytoplasm. Curr. Biol. 12, 1060-1067.

Durand, S., and Lykke-Andersen, J. (2013). Nonsense-mediated mRNA decay occurs during elF4F-dependent translation in human cells. Nat. Struct. Mol. Biol. 20, 702-709.

Eberle, A.B., Stalder, L., Mathys, H., Orozco, R.Z., and Mühlemann, O. (2008). Posttranscriptional gene regulation by spatial rearrangement of the 3' untranslated region. PLoS Biol. 6, e92.

Eberle, A.B., Lykke-Andersen, S., Mühlemann, O., and Jensen, T.H. (2009). SMG6 promotes endonucleolytic cleavage of nonsense mRNA in human cells. Nat. Struct. Mol. Biol. 16, 49-55.

Franks, T.M., Singh, G., and Lykke-Andersen, J. (2010). Upf1 ATPasedependent mRNP disassembly is required for completion of nonsense-mediated mRNA decay. Cell 143, 938-950.

Frischmeyer, P.A., and Dietz, H.C. (1999). Nonsense-mediated mRNA decay in health and disease. Hum. Mol. Genet. 8, 1893-1900.

Fukuhara, N., Ebert, J., Unterholzner, L., Lindner, D., Izaurralde, E., and Conti, E. (2005). SMG7 is a 14-3-3-like adaptor in the nonsense-mediated mRNA decay pathway. Mol. Cell 17, 537-547.

Gardner, L.B. (2010). Nonsense-mediated RNA decay regulation by cellular stress: implications for tumorigenesis. Mol. Cancer Res. 8, 295-308.

Gehring, N.H., Lamprinaki, S., Hentze, M.W., and Kulozik, A.E. (2009a). The hierarchy of exon-junction complex assembly by the spliceosome explains key features of mammalian nonsensemediated mRNA decay. PLoS Biol. 7, e1000120.

Gehring, N.H., Lamprinaki, S., Kulozik, A.E., and Hentze, M.W. (2009b). Disassembly of exon junction complexes by PYM. Cell 137, 536-548.

Hentze, M.W., and Izaurralde, E. (2013). Making sense of nonsense. Nat. Struct. Mol. Biol. 20, 651-653.

Hogg, J.R., and Goff, S.P. (2010). Upf1 senses 3'UTR length to potentiate mRNA decay. Cell 143, 379-389.

Holbrook, J.A., Neu-Yilik, G., Hentze, M.W., and Kulozik, A.E. (2006). NMD and Human Disease. In nonsense-mediated mRNA decay, L.E. Maquat, ed. (TX, USA: Landes Bioscience), pp. 111-119.

Hoskins, A.A., and Moore, M.J. (2012). The spliceosome: a flexible, reversible macromolecular machine. Trends Biochem. Sci. 37, 179-188.

Hosoda, N., Kim, Y.K., Lejeune, F., and Maquat, L.E. (2005). CBP80 promotes interaction of Upf1 with Upf2 during nonsense-mediated mRNA decay in mammalian cells. Nat. Struct. Mol. Biol. 12,
893-901.

Hosoda, N., Lejeune, F., and Maquat, L.E. (2006). Evidence that poly $(\mathrm{A})$ binding protein $\mathrm{C} 1$ binds nuclear pre-mRNA poly $(\mathrm{A})$ tails. Mol. Cell. Biol. 26, 3085-3097.

Huang, L., Lou, C.H., Chan, W., Shum, E.Y., Shao, A., Stone, E., Karam, R., Song, H.W., and Wilkinson, M.F. (2011). RNA homeostasis governed by cell type-specific and branched feedback loops acting on NMD. Mol. Cell 43, 950-961.

Huntzinger, E., Kashima, I., Fauser, M., Sauliere, J., and Izaurralde, E. (2008). SMG6 is the catalytic endonuclease that cleaves mRNAs containing nonsense codons in metazoan. RNA 14 2609-2617.

Hwang, J., and Kim, Y.K. (2013). When a ribosome encounters a premature termination codon. BMB Rep. 46, 9-16.

Hwang, J., Sato, H., Tang, Y., Matsuda, D., and Maquat, L.E. (2010). UPF1 association with the cap-binding protein, CBP80, promotes nonsense-mediated mRNA decay at two distinct steps. Mol. Cell 39, 396-409.

Ishigaki, Y., Li, X., Serin, G., and Maquat, L.E. (2001). Evidence for a pioneer round of mRNA translation: mRNAs subject to nonsense-mediated decay in mammalian cells are bound by CBP80 and CBP20. Cell 106, 607-617.

Isken, O., and Maquat, L.E. (2007). Quality control of eukaryotic mRNA: safeguarding cells from abnormal mRNA function. Genes Dev. 21, 1833-1856.

Isken, O., Kim, Y.K., Hosoda, N., Mayeur, G.L., Hershey, J.W., and Maquat, L.E. (2008). Upf1 phosphorylation triggers translational repression during nonsense-mediated mRNA decay. Cell 133 314-327.

Ivanov, P.V., Gehring, N.H., Kunz, J.B., Hentze, M.W., and Kulozik, A.E. (2008). Interactions between UPF1, eRFs, PABP and the exon junction complex suggest an integrated model for mammalian NMD pathways. EMBO J. 27, 736-747.

Kashima, I., Yamashita, A., Izumi, N., Kataoka, N., Morishita, R., Hoshino, S., Ohno, M., Dreyfuss, G., and Ohno, S. (2006). Binding of a novel SMG-1-Upf1-eRF1-eRF3 complex (SURF) to the exon junction complex triggers Upf1 phosphorylation and nonsense-mediated mRNA decay. Genes Dev. 20, 355-367.

Kervestin, S., and Jacobson, A. (2012). NMD: a multifaceted response to premature translational termination. Nat. Rev. Mol. Cell. Biol. 13, 700-712.

Kervestin, S., Li, C., Buckingham, R., and Jacobson, A. (2012). Testing the faux-UTR model for NMD: analysis of Upf1p and Pab1p competition for binding to eRF3/Sup35p. Biochimie 94, 1560-1571.

Kornblihtt, A.R., Schor, I.E., Allo, M., Dujardin, G., Petrillo, E., and Munoz, M.J. (2013). Alternative splicing: a pivotal step between eukaryotic transcription and translation. Nat. Rev. Mol. Cell Biol. 14, 153-165

Kugler, W., Enssle, J., Hentze, M.W., and Kulozik, A.E. (1995). Nuclear degradation of nonsense mutated beta-globin mRNA: a post-transcriptional mechanism to protect heterozygotes from severe clinical manifestations of beta-thalassemia? Nucleic Acids Res. 23, 413-418.

Kuhn, U., Gundel, M., Knoth, A., Kerwitz, Y., Rudel, S., and Wahle, E. (2009). Poly(A) tail length is controlled by the nuclear poly(A)binding protein regulating the interaction between poly $(A)$ polymerase and the cleavage and polyadenylation specificity factor. J. Biol. Chem. 284, 22803-22814.

Kuroha, K., Tatematsu, T., and Inada, T. (2009). Upf1 stimulates degradation of the product derived from aberrant messenger RNA containing a specific nonsense mutation by the proteasome. EMBO Rep. 10, 1265-1271.

Kurosaki, T., and Maquat, L.E. (2013). Rules that govern UPF1 binding to mRNA $3^{\prime}$ UTRs. Proc. Natl. Acad. Sci. USA 110 3357-3362.

Le Hir, H., Izaurralde, E., Maquat, L.E., and Moore, M.J. (2000a). The spliceosome deposits multiple proteins 20-24 nucleotides upstream of mRNA exon-exon junctions. EMBO J. 19, 6860-6869.

Le Hir, H., Moore, M.J., and Maquat, L.E. (2000b). Pre-mRNA splicing alters mRNP composition: evidence for stable association of proteins at exon-exon junctions. Genes Dev. 14, 1098-1108.

Lejeune, F., Li, X., and Maquat, L.E. (2003). Nonsense-mediated mRNA decay in mammalian cells involves decapping, deadenylating, and exonucleolytic activities. Mol. Cell 12, 675-687.

Lejeune, F., Ranganathan, A.C., and Maquat, L.E. (2004). elF4G is 
required for the pioneer round of translation in mammalian cells. Nat. Struct. Mol. Biol. 11, 992-1000.

Maquat, L.E., Hwang, J., Sato, H., and Tang, Y. (2010a). CBP80promoted mRNP rearrangements during the pioneer round of translation, nonsense-mediated mRNA decay, and thereafter. Cold Spring Harb. Symp. Quant. Biol. 75, 127-134.

Maquat, L.E., Tarn, W.Y., and Isken, O. (2010b). The pioneer round of translation: features and functions. Cell 142, 368-374.

McCracken, S., Fong, N., Rosonina, E., Yankulov, K., Brothers, G., Siderovski, D., Hessel, A., Foster, S., Shuman, S., and Bentley, D.L. (1997). 5'-Capping enzymes are targeted to pre-mRNA by binding to the phosphorylated carboxy-terminal domain of RNA polymerase II. Genes Dev. 11, 3306-3318.

McGlincy, N.J., and Smith, C.W. (2008). Alternative splicing resulting in nonsense-mediated mRNA decay: what is the meaning of nonsense? Trends Biochem. Sci. 33, 385-393.

Meaux, S., van Hoof, A., and Baker, K.E. (2008). Nonsense-mediated mRNA decay in yeast does not require PAB1 or a poly $(\mathrm{A})$ tail. Mol. Cell 29, 134-140.

Meijer, H.A., Kong, Y.W., Lu, W.T., Wilczynska, A., Spriggs, R.V., Robinson, S.W., Godfrey, J.D., Willis, A.E., and Bushell, M. (2013). Translational repression and elF4A2 activity are critical for microRNA-mediated gene regulation. Science 340, 82-85.

Mendell, J.T., Sharifi, N.A., Meyers, J.L., Martinez-Murillo, F., and Dietz, H.C. (2004). Nonsense surveillance regulates expression of diverse classes of mammalian transcripts and mutes genomic noise. Nat. Genet. 36, 1073-1078.

Millevoi, S., and Vagner, S. (2010). Molecular mechanisms of eukaryotic pre-mRNA $3^{\prime}$ end processing regulation. Nucleic Acids Res. 38, 2757-2774.

Mühlemann, O., and Lykke-Andersen, J. (2010). How and where are nonsense mRNAs degraded in mammalian cells? RNA Biol. 7, 28-32.

Nagy, E., and Maquat, L.E. (1998). A rule for termination-codon position within intron-containing genes: when nonsense affects RNA abundance. Trends. Biochem. Sci. 23, 198-199.

Neu-Yilik, G., Amthor, B., Gehring, N.H., Bahri, S., Paidassi, H., Hentze, M.W., and Kulozik, A.E. (2011). Mechanism of escape from nonsense-mediated mRNA decay of human beta-globin transcripts with nonsense mutations in the first exon. RNA 17, 843-854.

Ni, J.Z., Grate, L., Donohue, J.P., Preston, C., Nobida, N., O'Brien, G., Shiue, L., Clark, T.A., Blume, J.E., and Ares, M., Jr. (2007) Ultraconserved elements are associated with homeostatic control of splicing regulators by alternative splicing and nonsensemediated decay. Genes Dev. 21, 708-718.

Ohnishi, T., Yamashita, A., Kashima, I., Schell, T., Anders, K.R., Grimson, A., Hachiya, T., Hentze, M.W., Anderson, P., and Ohno, S. (2003). Phosphorylation of hUPF1 induces formation of mRNA surveillance complexes containing hSMG-5 and hSMG-7. Mol. Cell 12, 1187-1200.

Okada-Katsuhata, Y., Yamashita, A., Kutsuzawa, K., Izumi, N., Hirahara, F., and Ohno, S. (2012). N- and C-terminal Upf1 phosphorylations create binding platforms for SMG-6 and SMG5:SMG-7 during NMD. Nucleic Acids Res. 40, 1251-1266.

Peixeiro, I., Inácio, A.., Barbosa, C., Silva, A.L., Liebhaber, S.A., and Româo, L. (2012). Interaction of PABPC1 with the translation initiation complex is critical to the NMD resistance of AUG-proximal nonsense mutations. Nucleic Acids Res. 40,1160-1173.

Rebbapragada, I., and Lykke-Andersen, J. (2009). Execution of nonsense-mediated mRNA decay: what defines a substrate?
Curr. Opin. Cell Biol. 21, 394-402.

Rufener, S.C., and Mühlemann, O. (2013). elF4E-bound mRNPs are substrates for nonsense-mediated mRNA decay in mammalian cells. Nat. Struct. Mol. Biol. 20, 710-717.

Saltzman, A.L., Kim, Y.K., Pan, Q., Fagnani, M.M., Maquat, L.E. and Blencowe, B.J. (2008). Regulation of multiple core spliceosomal proteins by alternative splicing-coupled nonsense-mediated mRNA decay. Mol. Cell. Biol. 28, 4320-4330.

Sato, H., and Maquat, L.E. (2009). Remodeling of the pioneer translation initiation complex involves translation and the karyopherin importin beta. Genes Dev. 23, 2537-2550.

Serin, G., Gersappe, A., Black, J.D., Aronoff, R., and Maquat, L.E. (2001). Identification and characterization of human orthologues to Saccharomyces cerevisiae Upf2 protein and Upf3 protein (Caenorhabditis elegans SMG-4). Mol. Cell. Biol. 21, 209-223.

Shatkin, A.J., and Manley, J.L. (2000). The ends of the affair: capping and polyadenylation. Nat. Struct. Biol. 7, 838-842.

Shigeoka, T., Kato, S., Kawaichi, M., and Ishida, Y. (2012). Evidence that the Upf1-related molecular motor scans the $3^{\prime}$-UTR to ensure mRNA integrity. Nucleic Acids Res. 40, 6887-6897.

Singh, G., Rebbapragada, I., and Lykke-Andersen, J. (2008). A competition between stimulators and antagonists of Upf complex recruitment governs human nonsense-mediated mRNA decay. PLoS Biol. 6, e111.

Singh, G., Kucukural, A., Cenik, C., Leszyk, J.D., Shaffer, S.A., Weng, Z., and Moore, M.J. (2012). The cellular EJC interactome reveals higher-order mRNP structure and an EJC-SR protein nexus. Cell 151, 750-764.

Takahashi, S., Araki, Y., Ohya, Y., Sakuno, T., Hoshino, S., Kontani, K., Nishina, H., and Katada, T. (2008). Upf1 potentially serves as a RING-related E3 ubiquitin ligase via its association with Upf3 in yeast. RNA 14, 1950-1958.

Topisirovic, I., Svitkin, Y.V., Sonenberg, N., and Shatkin, A.J. (2011) Cap and cap-binding proteins in the control of gene expression. Wiley Interdiscip. Rev. RNA 2, 277-298.

Tran, E.J., and Wente, S.R. (2006). Dynamic nuclear pore complexes: life on the edge. Cell 125, 1041-1053.

Trcek, T., Sato, H., Singer, R.H., and Maquat, L.E. (2013). Temporal and spatial characterization of nonsense-mediated mRNA decay. Genes Dev. 27, 541-551.

Unterholzner, L., and Izaurralde, E. (2004). SMG7 acts as a molecular link between mRNA surveillance and mRNA decay. Mol. Cell 16, 587-596.

Wang, D., Zavadil, J., Martin, L., Parisi, F., Friedman, E., Levy, D., Harding, H., Ron, D., and Gardner, L.B. (2011). Inhibition of nonsense-mediated RNA decay by the tumor microenvironment promotes tumorigenesis. Mol. Cell. Biol. 31, 3670-3680.

Yamashita, A., Izumi, N., Kashima, I., Ohnishi, T., Saari, B., Katsuhata, Y., Muramatsu, R., Morita, T., Iwamatsu, A., Hachiya, T., et al. (2009). SMG-8 and SMG-9, two novel subunits of the SMG-1 complex, regulate remodeling of the mRNA surveillance complex during nonsense-mediated mRNA decay. Genes Dev. 23, 1091-1105

Yepiskoposyan, H., Aeschimann, F., Nilsson, D., Okoniewski, M., and Mühlemann, O. (2011). Autoregulation of the nonsensemediated mRNA decay pathway in human cells. RNA 17, 21082118.

Zhang, J., and Maquat, L.E. (1997). Evidence that translation reinitiation abrogates nonsense-mediated mRNA decay in mammalian cells. EMBO J. 16, 826-833. 